GLOBAL JOURNAL OF COMMUNITY MEDICINE VOL. 2 NO. 1 \& 2 2009: 21 - 25 COPYRIGHT@ BACHUDO SCIENCE CO. LTD PRINTED IN NIGERIA. ISSN 1597 - 9857

\title{
MALE BREAST CANCER IN CALABAR NIGERIA: A TWENTY YEAR EXPERIENCE (1983-2002)
}

\author{
M. S UMOH, M. E. ASUQUO, A. A. OTU AND EKANEM IMAOBONG
}

(Received 3 July, 2008; Revision Accepted 12 September, 2008)

\section{ABSTRACT}

Male breast cancer is rare worldwide. The highest incidence of 2.1 per 100,000 is recorded in Louisiana USA. The record for Africa varies from 0.2 per 100,000 in Gambia to 0.8 per 100,000 in Mali Breast cancer has been erroneously thought to be entirely a female disease in the tropics. This ignorance makes late presentation almost the rule in Nigeria as reported by authors in various part of the country. Breast cancer is the commonest malignancy in Calabar. From the Calabar cancer registry record, 105 cases of breast cancer were seen in 1995 through 1998. Of these 5 patients (4.7\%) were male. A review of 30 cases of male breast cancer seen in UCTH between Jan 1983 to Dec 2002 is being studied to look at the clinical presentation, histological pattern and management. They were aged 19 to $85 \mathrm{yrs}$ with mean of 53.1yrs. We observed two peaks at $3^{\text {rd }}$ and $6^{\text {th }}$ decades of life. More than $80 \%$ (25 cases) presented with painless lump and palpable axillary lymph nodes. Over $50 \%$ were on the right. Three patients also had nipples changes. Gross weight loss was associated with very advanced cases. The interval before presentation ranged from 3 to 84 months. All had mastectomy and axillary nodes dissection. Adjuvant chemotherapy was also used. Diagnosis was confirmed by histopathological examination of removed specimen. The follow up was generally poor. However one patient survived beyond ten years.

KEYWORDS: Male Breast Cancer, Calabar, Nigeria

\section{INTRODUCTION}

Except for the transient physiological enlargement (Gynaecomastia) at puberty the male breast remains rudimentary throughout life. Nonetheless the male breast is still subject to neoplastic changes as in the female.

Louisiana in the United States of America has the highest incidence of $2.1 / 100,000$ worldwide. Relative incidence in the African population ranges from $0.2 / 100,000$ in the Gambia to $0.8 / 100,000$ in
Mali republic; International Agency for Research in Cancer (IARC) Cancer Incidence in Five Continents, 2002. Very little has been written on male breast cancer. It is believed to be similar to the female; however the male breast is unique because it is not subject to cyclical hormonal changes as in the female. Most texts are completely silent on it and most men particularly in developing countries erroneously may believe that breast cancer is purely a female disease. Adverts and posters on self breast examination are female oriented. We wish to

M. S Umoh, Department of Surgery, College of Medical Sciences, University of Calabar, Calabar, Nigeria.

M. E. Asuquo, Department of Surgery, College of Medical Sciences, University of Calabar, Calabar, Nigeria.

A. A. Otu, Department of Surgery, College of Medical Sciences, University of Calabar, Calabar, Nigeria.

Ekanem Imaobong, Department of Pathology, College of Medical Sciences, University of Calabar, Calabar Nigeria 
contribute to the growing awareness that male breast is real. Efforts should be directed at early detection and appropriate treatment.

\section{MATERIALS AND METHOD}

This is a retrospective study of male breast cancer in the University of Calabar Teaching Hospital (UCTH) between January 1983 and December 2002. Case files of patients with male breast cancer were retrieved from the records department and reviewed. The clinicopathological features and treatment modalities were studied. Prognosis could not be assessed because of poor follow-up. The problems of diagnosis, availability of treatment options and follow-up are noted.

\section{RESULTS}

Thirty cases of male breast cancer were seen in the UCTH between January 1983 and December 2002 a period of 20years. The age distribution pattern is noteworthy. One half of the patients were aged 51-70 yrs.

TABLE I. $(\mathrm{n}=30)$

Age distribution of male breast cancer patients

Age group

(yrs)

$<20$

$21-30$

No.of Patients (\%)

$31-40$

$41-50$

$51-60$

$61-70$

$71-80$

$>80$

Unknown

TOTAL

The clinical presentation was predominantly as a painless lump under the nipple-areola complex. Other symptoms were nipple discharge and palpable axillary lymph nodes. Pain, ulceration and weight loss were associated with advanced disease.

\section{Clinical features at \\ presentation in male breast \\ cancer Pts $(n=30)$}

TABLE II

Feature

Lump

Pain

Nipple Discharge

Nipple Retraction

Ulcer

Weight Loss

Axillary Nodes

Some patients presented with more than one symptom. Of importance is the large number (24) with axillary lymph nodes involvement.

The duration of symptoms prior to presentation ranged from 3 to 84 months.
No. of patients Percentage

$\begin{array}{rr}28 & 93.3 \\ 8 & 26.6 \\ 1 & 3.3 \\ 2 & 6.7 \\ 5 & 16.7 \\ 4 & 13.3 \\ 24 & 80\end{array}$

Only 2 patients were seen within three months. The absence of pain and the lower cosmetic consciousness of the man probably contributed significantly to the late presentation. 
Histological variants and subtypes in male breast

Ca. Pts $(n=30)$

\section{TABLE III}

\section{Type Pts}

EPITHELIAL

Intraductal

Invasive Ductal

NOS

Adenocystic carcinoma

Adnex Accrine

Papillary

MESENCHYMAL

Malignant histiocytoma

Fibrosarcoma

TOTAL

Most of the patients $(70 \%)$ had infiltrating ductal carcinoma. None of the cases was tested for hormone receptors. Treatment consisted of surgical extirpation of the breast and axillary dissection as well as cyclical cyclophosphamidebased combination chemotherapy. Radiotherapy was not available. Prognosis could not be done due to deficient records and follow-up compliance. However one patient with stage one disease was followed up for 10years. Most patients were lost to follow-up after 2years.

\section{DISCUSSION}

Breast cancer is probably the commonest and most discussed malignancy malignancy in the literature. However attention has focused mainly on the female variety. There are scanty reports on male breast cancer. This may erroneously give the impression that the affliction is entirely a female problem. Even some physicians may dismiss a breast complaint from a man as nothing to worry about. Such might likely result in terrible consequence. The case of John W Nicks in Port Washington, New York,
No. of

Percentage

27

90

$2 \quad 6.7$

21

70

1

3.3

2

6.7

1

3

10

$2 \quad 6.7$

1

30

USA is an example. John Nick died in 1991 at the age of 58 from male breast cancer, a disease that he did not know he had until it was too late. He however had made a complaint of nipple change a couple of years back to his primary physician; John Nick's Foundation Inc 1995.

Male breast cancer is rare. It is generally believed to account for less than $1 \%$ of all cancers of the breast. That means it is 100 times less common than female breast cancer; Jon G Jonsson et al 1998. However this seems not the case in the tropics. Figures ranging from $2.4 \%$ in Nigeria to $10.4 \%$ in Ethiopia have been reported by various authors; DOS Ajayi et al, D Dogo et al 2006, Adeniyi KA et al 1997, Hassen I et al 1995, Ihekwaba FN 1993, Agadiuno PU 1987, Okobia MN et al 2001, Tessema Ersumo 2006

The presenting characteristics and treatment are similar to that of female breast cancer. Male breast cancer is however unique because the male breast is not subject to monthly cyclical hormonal changes. The sparseness of breast tissue might facilitate early dermal lymphatic spread and regional and distant metastasis as a developing lump is in close 
proximity to both overlying skin and the underlying pectoral fascia. Also mammography is not routinely used; Memorial Sloan-Kettering Cancer Centre 2000,D Pereiral et al 2003. The use of anti-oestrogen therapy may be of limited value.

This study shows that most patients presented with a painless breast lump under the areola. Nipple changes were occasional. Associated pains, ulceration and weight loss indicated advanced disease with widespread secondaries. Diagnosis was usually clinical as more than $80 \%$ presented at advanced stage. The use of fine needle aspiration cytology was introduced in the late eighties. Mammography was not available. The paucity of breast tissue density in the male breast might hamper mammography.

The commonest histological type was infiltrating ductal. This corroborates with the findings of other reports from various part of Nigeria .The report by $D$ Pereiral et al found a high percentage $(17 \%)$ of papillary type unlike ours with about $3 \%$. This may be because papillary breast cancer is commoner in Caucasians. Burkitts' lymphoma, inflammatory breast cancer and Paget's disease were not seen in our series.

All patients had mastectomy and axillary dissection. Cyclophosphamide-based cyclical chemotherapy was used for patient with advanced disease. The adjuvant chemotherapy comprised cyclophosphamide, 5 flouracil, methotrexate and prednisolone. The use of hormonal manipulation consisted of mainly orchiectomy for cases seen in earlier years and tamoxifen in later cases. Radiotherapy was not available and so was not used as primary or adjunctive therapy.

The prognosis in male breast cancer was hitherto thought to be worse than in the female. Several studies have proved this to be untrue. Recent statistics have shown that stage for stage the prognosis is similar; Sharon $\mathrm{H}$ Giordan etal 2002, Joshi MG et al 1996.

The challenges remain early detection; availability, accessibility and affordability of treatment options and expertise.

Education of both physician and the public is necessary if situations like the John W Nick story in the USA are to be avoided. Studies for breast cancer genes $\mathrm{BRCA}_{2}$ should be carried out since this is a risk factor for developing cancer particularly if there is a positive family history of breast, ovarian and colonic cancer.

\section{CONCLUSION}

Male breast cancer is real. The clincopathological characteristics, management and prognosis are same as in the female.

With increased awareness the chances of early detection may be better since the sparse breast tissue density would make a developing lump prominent. Awareness campaigns by patients and relatives e.g. John W Nick's Foundation in the USA is a step in the right direction.

Coordinated and perhaps populationbased studies are needed to establish the overall prevalence of male breast cancer in Nigeria. There is the need to make all treatment options and expertise available, accessible and affordable to provide optimal healthcare to our patients.

\section{REFERENCE}

Adeniyi, K. A., Adelusola, K. A., Odesanmi, W. O. and Fadiran, O. A., 1997. Histopathological analysis on cancer of the male breast in Ile-Ife Nigeria: East Afr Med J : 74(7):455-7

Agadiuno, P. U., 1987. Cancer of the male breast: Analysis of Forty-three cases in Ibadan Nigeria Afr J Med Sci. 16(1):1526

Ajayi, D. O. S., Osegbe, D. N. and Ademiluyi, S. A., 2006. Carcinoma of the male breast in West Africans and a review of world literature; Cancer 50 (8): 1664-1667 (Published online Jun 28 2006).

Dogo, D., Gali, B. M. and Nggada, H. A., 2006. Male breast cancer in Northeastern Nigeria; Nig Journal of Clinical Practice. 9 (2): $139-14$

Hassen, I. and Mabogunje, O., 1995. Cancer of the male breast in Zaria Nigeria; East Afr Med J. 72(7):457-8

Ihekwaba, F. N., 1993. Management of male breast cancer in Nigeria; Postgrad Med $\mathrm{J}$ 69(813):562-5 
International Agency for Research in Cancer (IARC)., 2002. Cancer Incidence in five Continents; Vol VIII No155 Chapter 9 edited by DM Parkin, SL Whelan, J Ferlay L Teppo and DB Thomas

Jon G Jonsson, Bjami A Angnarsson, Steinunn Thorlacius, Jorunn E Eyfjora and Hrafn Tulinius., 1998. Male breast cancer in Iceland; Inter J of Cancer, 65 (4): 446-449. (Published online Dec 1998)

John W Nick's Foundation Inc., 1995. Our Mission: To educate the public on men's risk for breast cancer. www.johnwnickfoundation.org/stories.

Joshi, M. G., Lee, A. K., Loda, M., Camus, M. G., Pedersen, C., Heatley, G. J. and Hughes, K. S., 1996. Male breast carcinoma: an evaluation of prognostic factors contributing to a poorer outcome; Cancer; 77(3):490-8.
Memorial Sloan-Kettering Cancer Centre: Breast cancer in men April 2000. www.mskcc.org/mskcc/html/1879.cfm.

Okobia, M. N. and Osime, U. 2001. Clinicopathological study of cancer of the male breast in Benin-City Nigeria; Afr J Reprod Health 5(2):56-62.

Pereiral, D., et al., 2003. Male Breast Cancer Similar to Breast cancer in women. (Presented at the European Conference of Clinical Oncology Meeting, Abstract No. 379

Sharon H Giordan., Aman U. Buzdar and Gabriel N Hortobagyi., 2002. Breast cancer in men, Ann Intern Med 137(8): 678-687.

Tessema Ersumo., 2006. Breast cancer in Ethiopian population, Addis Ababa; East and Central African Journal of Surgery, .11(1): 81-86. 